\title{
STUDIES OF TOTAL PULMONARY CAPACITY AND ITS SUBDIVISIONS. V. NORMAL VALUES IN FEMALE SUBJECTS
}

\author{
By ALBERTO HURTADO, WALTER W. FRAY, NOLAN L. KALTREIDER \\ AND WILLIAM D. W. BROOKS 1 \\ (From the Department of Medicine of the School of Medicine and Dentistry of the \\ University of Rochester and the Medical Clinic and Division of Radiology \\ of the Strong Memorial and Rochester Municipal Hospitals, Rochester, \\ New York)
}

(Received for publication September 13, 1933)

Studies of the total pulmonary capacity and its subdivisions have been made in this clinic during the last two years, in an attempt to obtain a quantitative estimation of the degree of functional disability in cases of chronic pulmonary disease. It was found that the normal values gathered from the literature were insufficient to afford an adequate basis for the detection of pathological alterations, and preliminary studies were consequently made in healthy subjects. The results of measurements made in fifty normal male subjects have been presented in previous papers (11), (12). The data show definite limits of variation for the relative values of some of the subdivisions of the total pulmonary capacity, as well as a definite correlation between the pulmonary capacity and combined physical and radiological measurements of the chest. By means of these measurements the pulmonary capacity in a given normal adult male subject can be predicted with a fair degree of accuracy. Since it seemed probable that the same formula can not be applied in the case of normal female subjects, a similar. series of observations has been made in them. The results are presented in this communication.

\section{METHODS}

As in the previous study, the total pulmonary capacity and its subdivisions were measured by means of Christie's method of oxygen dilution without forced breathing. Complete details will be found in that author's original description (5), and further details as to its use in this clinic are given in the first paper of this series (11). It may be mentioned, that we have become more convinced of the desirability of measuring the residual air by this method, rather than the volume of air remaining in the lungs at the end of a normal expiration (called " functional residual air" by Christie and "mid capacity" by us). 2 By

1 Travelling Fellow of the Rockefeller Foundation; Fer̈eday Fellow, St. John's College, Oxford.

${ }^{2}$ Correction of value of residual air for nitrogen excretion from the blood.After this communication was written investigations were made as to the ap- 
making duplicate measurements, it was found that better checks were obtained by measuring the residual air, especially since graphic registration of the forced expiration was made at the beginning and at the end of the period of mixing with the contents of the spirometer so that the degree of cooperation of the subject in deflating to the residual level could be accurately ascertained. It has also been observed that a more thorough mixing takes place between the air in the lungs and the oxygen in the spirometer, because of the deep inspiration which follows forced expiration at the beginning and the smaller volume of air contained in the lungs at the residual level. The method as described by Christie may be used advantageously nevertheless, in subjects who are unable

plicability of this method in the determination of the residual air in such cases as pulmonary emphysema, where this subdivision of the pulmonary capacity is expected to be increased. In such a case the attainment of complete mixing between the gas mixture in the spirometer and the air in the lungs may be questioned. It has been found in these pathological conditions, as well as in normal people, that repeated duplicate determinations check closely, providing that the time of the rebreathing period (seven minutes) remained constant. Our results then are in agreement with those of most investigators who found that at the end of five to seven minutes there is complete mixing in all cases. Prolongation of this time (to 8,10 or 12 minutes) leads to an almost constant and proportional increase in the value found for the residual air. It appears that these increasing values are possibly not due to improper mixing but rather to the continuous excretion of nitrogen from the blood into the alveolar air, as shown by Campbell and Hill (J. Physiol., 1931, 71, 309).

The above findings stress the importance of keeping constant the time of the rebreathing period in all determinations. In this series of cases, and in those already reported, the rebreathing period has been from seven to eight minutes.

From the investigations of Hill, Long and Lupton (Proc. Roy. Soc., B, 1924, 97, 84) and Campbell and Hill (J. Physiol., 1931, 71, 309) Christie has estimated that approximately $65 \mathrm{cc}$. of nitrogen are excreted from the blood into the spirometer-lung system during the seven minutes of rebreathing, and corrects for this factor by subtracting this volume from the final result. The formula given by Christie is as follows:

$$
x=\frac{y(a-b)}{79.1-y}-d-80
$$

where $x=$ the lung volume in cc.; $y=$ percentage of nitrogen in the circuit at end of experiment; $a=$ oxygen in the spirometer at beginning of experiment in cc.; $b=$ oxygen absorbed during experiment in cc., and $d=$ dead space in spirometer circuit in cc.

According to the above formula the nitrogen excretion has been corrected only in terms of gas volume added to the system during the rebreathing time, disregarding the fact that it has increased the nitrogen percentage found in the system at the end of the experiment. The formula was developed by equating the volume of nitrogen in the system at the beginning of the experiment against the volume present at the end. By taking into account, in Christie's original equation, any volume of nitrogen $(n)$ excreted into the spirometer-lung system and solving for $x$ the following is obtained:

$$
x=\frac{y(a-b)-100 n}{79.1-y}-d .
$$


to cooperate satisfactorily in making the maximum effort necessary to deflate the lungs to the residual level.

In most instances two estimations were made, and the results corrected for temperature $\left(37^{\circ} \mathrm{C}\right.$.) and complete saturation with water vapor. All observations were carried out in the afternoon after a preliminary rest of at least 20 minutes, the subjects being in the recumbent position with two pillows to serve as a head rest.

A measurement of the respiratory "dead space" was also made in each case under conditions of rest, and in the calculation of this volume the HaldanePriestley formula:

$$
\text { Dead space }=\text { Tidal volume }-\frac{\text { Tidal volume } \times \text { per cent } \mathrm{CO}_{2} \text { expired air }}{\text { per cent } \mathrm{CO}_{2} \text { alveolar air }}-k
$$

(where $k$ is the dead space of the apparatus-in our case $40 \mathrm{cc}$.) was used. In the collection of the alveolar air sample, a modification of the Fridericia (7) method was employed because of the difficulties usually met with in obtaining a true alveolar air sample from untrained subjects with the well known HaldanePriestley method. The apparatus used is shown in Figure 1. A mouthpiece, attached to the apparatus by a short and thick rubber tubing, is provided with a valve which allows free and unobstructed passage of the air forwards, but which prevents the return of the air if the subject attempts to inspire before the sample is trapped in the apparatus. The stopcocks have bores $6 \mathrm{~mm}$. in cliameter and thus offer very little resistance to the passage of air through them. The whole apparatus is mounted on a wooden frame, and is connected below to a mercury reservoir which is suspended by a hook on the back of the frame. This frame is fitted to slide into a specially constructed table mounted on casters, so that the whole may be wheeled in front of the subject who sits comfortably in a chair. The sample of the alveolar air is obtained in the following manner: The apparatus is set up as shown in Figure 1. Stopcock $S^{1}$ connects the rubber tubing of the mouth piece to bulb $A$, while stopcock $S^{2}$ connects this bulb and $F$ with the outside air. The connecting link $F$ of the apparatus is filled with mercury up to stopcock $S^{2}$. The subject holds the mouthpiece in his hand and after a few minutes of normal breathing, immediately before a normal expiration is concluded, he is asked quickly to place the mouthpiece in between his lips and make a forced and prolonged expiration. At its conclusion, stopcocks $S^{1}$ and $S^{2}$ are quickly turned with $S_{2}$ connecting $F$ and outer air so that the last part of the expiratory air is trapped in bulb $A$. The frame is then placed on a support close to the Van Slyke manometric apparatus for the transfer of the gas sample. The mouthpiece and connecting tube are removed, and a glass capillary tube, bent at right angles at both ends, is con-

Therefore if $65 \mathrm{cc}$. are excreted during the time of the experiment we believe the formula should be:

$$
x=\frac{y(a-b)-6500}{79.1-y}-d .
$$

The application of the latter formula will give lower values for the residual air than those obtained from the former. Consequently the values given in this series of cases, as well as in the preceding ones, for this subdivision of the pulmonary capacity are probably 100 to $150 \mathrm{cc}$. too high. Since this is a constant, and probably not a very significant error, it does not invalidate our results, and permits comparative studies to be made with pathological cases. 


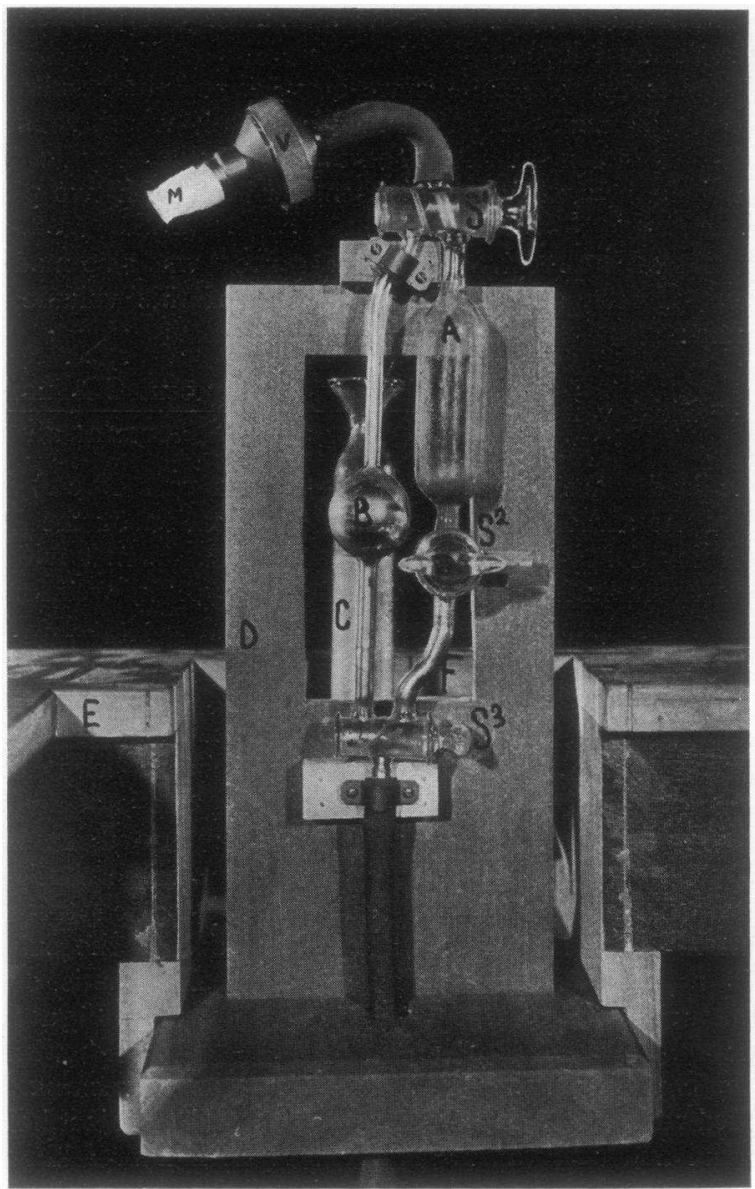

Fig. 1. Apparatus Used for Obtaining Alveolar Air Samples

$M$. Mouthpiece. $V$. Expiratory valve. $A$. Bulb of about $60 \mathrm{cc}$. capacity. $B$. Bulb of about 25 cc. capacity. $C$. Mercury reservoir. $S^{1}$. Stopcock with double bore (one $=6 \mathrm{~mm}$. wide). $S^{2}$. Three way stopcock. $S^{3}$. Stopcock with double bore. $D$. Wooden frame. E. Table. $F$. Connecting tube between stopcocks $S^{2}$ and $S^{3}$.

nected by means of a short thick rubber tubing. The other end is provided with a rubber tip which fits into the receiving cup of the Van Slyke apparatus. Stopcocks $S^{1}$ and $S^{3}$ are turned appropriately, and by raising the mercury reservoir the connecting tube and half of the receiving cup are filled with mercury from bulb $B$. The air sample is then transferred, either by previously making a vacuum in the 50-cc. chamber of the Van Slyke apparatus and then establishing a communication with the air sample, or by allowing the mercury of the reservoir to displace the samples from bulb $A$ into the chamber.

Incidentally, it may be mentioned that we have found it convenient to use gas sampling apparatus of the type just described (without stopcock $S^{2}$ ). The double bulb arrangement facilitates not only the washing of any dead space 
between the sampler and the gas to be obtained, but also the transfer of the sample to the Van Slyke manometric apparatus for analysis.

Samples were taken in the sitting position because of the larger volume of reserve air in this posture, thus facilitating the process of obtaining true alveolar air. The results showed the mean value of the alveolar $\mathrm{CO}_{2}$ percentage in this series to be $5.77 \pm 0.04$ per cent. The tidal air was obtained immediately afterwards with the subject in the same posture. The subject breathed through a mouthpiece from the room air into a Tissot spirometer of 100-liter capacity, which was provided with a recording pen and kymograph. Thus the depth, as well as the rate, of the breathing was recorded. During several minutes of preliminary breathing the dead space of this spirometer was washed with expired air. Tidal air was then collected over a period of from three to four minutes, so that the respiratory dead space as calculated by the formula just given corresponds to the average tidal volume during that time. The mean value of the $\mathrm{CO}_{2}$ percentage of the tidal air was $3.50 \pm 0.03$ per cent in the fifty cases.

External chest measurements were taken in all subjects, and the "chest volume" calculated from the product of the three dimensions (depth, width and height) according to the method of Lundsgaard and Van Slyke (16). Complete radiological measurements were also made, according to the special technique described in a previous publication (12), which consists of obtaining a double exposure radiograph of the chest, first at maximum expiration and immediately afterwards at maximum inspiration, the subject being in recumbency. The area of the lung fields in square centimeters, multiplied by the corresponding depth (in $\mathrm{cm}$.) of the chest, measured externally, is designated the "radiological chest volume." Theoretically, the latter should represent more accurately the true value of the chest cavity, since it takes into consideration the diaphragmatic level, than any value derived from external measurements alone. Furthermore, from the same film it is possible to estimate the expansion of the lungs from the difference between the areas of the lung fields at maximum expiration and inspiration; the lateral expansion of the chest; the excursion of the diaphragm; and finally, the degree of rib movement.

\section{MATERIAL}

Measurements of the total pulmonary capacity and its subdivisions have been made in a series of fifty healthy female subjects, varying in age from 18 to 34 years, with a mean of 23.1 years. The physical characteristics (Table I), show wide variations in the size of the body and the chest, as well as in the shape of the latter. No selective criterion as to any of these characteristics was used in accepting these subjects, so it would seem probable that these cases are fairly representative of the various constitutional types usually encountered at this age period. All of them were submitted to physical and fluoroscopic examination of the chest.

These subjects were students either of the College for Women of the University of Rochester, or of the School of Nursing (Strong Memorial Hospital) of the same university. ${ }^{3}$

${ }^{3}$ To Prof. Merle Spurrier and to Miss Clare Dennison, Director of the School of Nursing, we are greatly indebted for the kindly help which made this work possible. 
TABLE I

Age and physical characteristics of the subjects examined

\begin{tabular}{|c|c|c|c|c|}
\hline & Mean & $\begin{array}{l}\text { Standard } \\
\text { deviation }\end{array}$ & $\begin{array}{c}\text { Coefficient } \\
\text { of } \\
\text { variation }\end{array}$ & Variations \\
\hline 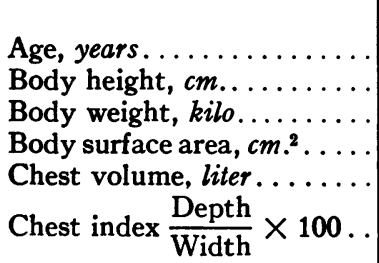 & $\begin{array}{r}23.1 \pm 0.32^{*} \\
163.4 \pm 0.40 \\
57.2 \pm 0.89 \\
160.0 \pm 1.29 \\
6.44 \pm 0.11 \\
71.9 \pm 0.69\end{array}$ & $\begin{array}{r}3.4 \pm 0.23^{*} \\
4.2 \pm 0.28 \\
9.4 \pm 0.63 \\
13.6 \pm 0.92 \\
1.15 \pm 0.08 \\
7.3 \pm 0.49\end{array}$ & $\begin{array}{c}\text { per cent } \\
14.6 \\
2.6 \\
16.4 \\
8.5 \\
17.9 \\
10.1\end{array}$ & $\begin{array}{cl}18 & -34 \\
152 & -177.5 \\
42 & -83.2 \\
136 & -189 \\
4.60-9.41 \\
57.2 & -100.0\end{array}$ \\
\hline
\end{tabular}

* Probable error.

\section{Normal values given in the literature 4}

The literature of the subject, with the exception of measurements of the vital capacity, offers relatively few values of the total pulmonary capacity and its subdivisions in normal female subjects. Quite frequently the results obtained in both male and female subjects are presented together. This seems undesirable, for it appears from the results of this investigation that differences between the sexes exist. A study of the values recorded in the literature is further. complicated, partly on account of variations in the methods and technique used, and partly because of lack of uniformity in body posture. The nomenclature of the subdivisions of the pulmonary capacity is furthermore by no means standardized.

In Table II are summarized the results of the more important series of determinations made in normal female subjects since the investigation of Lundsgaard and Van Slyke (16) in 1918. There are included seven cases reported by these investigators; eight cases by Lundsgaard and Schierbeck (17) and seven cases by Binger (3), a total of 22 cases. The nomenclature differs from ours in that the "mid capacity" represents the

${ }^{4}$ It may be convenient to summarize briefly the nomenclature which we have adopted:

Residual air is the amount of air remaining in the lungs after the fullest possible expiration.

Mid capacity is the amount of air remaining in the lungs after a normal expiration.

Vital capacity is the amount of air expired in the fullest possible expiration following the deepest possible inspiration. Vital capacity is the sum of the complementary and reserve volumes.

Total capacity is the sum of the residual air and the vital capacity.

Complementary air is the volume of air inspired from the position of mid capacity to that of maximum possible inflation. It includes the tidal air.

Reserve air is the amount of air expired from the mid capacity position to maximum possible deflation. 
TABLE II

Normal values of pulmonary capacity from the literature *

\begin{tabular}{|c|c|c|c|c|}
\hline \multirow[b]{2}{*}{$\begin{array}{l}\text { Pulmonary } \\
\text { capacity }\end{array}$} & \multicolumn{4}{|c|}{ Absolute values } \\
\hline & Mean & $\begin{array}{l}\text { Standard } \\
\text { deviation }\end{array}$ & $\begin{array}{c}\text { Coefficient } \\
\text { of } \\
\text { variation }\end{array}$ & Variations \\
\hline $\begin{array}{l}\text { Total capacity } \ldots \ldots \ldots \ldots \ldots \ldots \\
\text { Vital capacity } \ldots \ldots \ldots \ldots \ldots \\
\text { Complementary air } \ldots \ldots \ldots \ldots \\
\text { Reserve air. } \ldots \ldots \ldots \ldots \ldots \ldots \ldots \\
\text { Mid capacity } \ldots \ldots \ldots \ldots \ldots \\
\text { Residual air } \ldots \ldots \ldots \ldots \ldots \ldots\end{array}$ & $\begin{array}{l}\text { liters } \\
4.41 \\
3.18 \\
1.70 \\
1.52 \\
2.76 \\
1.23\end{array}$ & $\begin{array}{l}\text { liters } \\
0.62 \\
0.33 \\
0.32 \\
0.28 \\
0.40 \\
0.28\end{array}$ & $\begin{array}{c}\text { per cent } \\
14.0 \\
10.3 \\
18.8 \\
18.2 \\
14.4 \\
22.5\end{array}$ & $\begin{array}{c}\text { liters } \\
3.08-5.50 \\
2.20-3.88 \\
1.20-2.31 \\
1.00-2.08 \\
1.88-3.57 \\
0.75-1.75\end{array}$ \\
\hline
\end{tabular}

Relative values (total capacity 100 per cent)

\begin{tabular}{|c|c|c|c|c|}
\hline 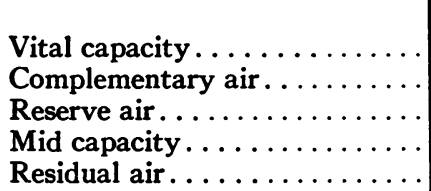 & $\begin{array}{l}\text { per cent } \\
72.0 \\
37.7 \\
34.0 \\
62.5 \\
28.2\end{array}$ & $\begin{array}{c}\text { per cent } \\
4.6 \\
3.9 \\
4.3 \\
3.8 \\
5.5\end{array}$ & $\begin{array}{c}\text { per cent } \\
6.4 \\
10.4 \\
12.7 \\
6.2 \\
19.4\end{array}$ & $\begin{array}{l}\text { per cent } \\
62-82 \\
30-46 \\
24-46 \\
54-70 \\
18-40\end{array}$ \\
\hline
\end{tabular}

Relative values (vital capacity 100 per cent)

\begin{tabular}{|c|c|c|c|c|}
\hline $\begin{array}{l}\text { Complementary air . . . . . . . } \\
\text { Reserve air . . . . . . . . . . . . . . . . . . . . . . } \\
\text { Mid capacity } \\
\text { Residual air . . }\end{array}$ & $\begin{array}{c}\text { per cent } \\
52.0 \\
48.2 \\
62.5 \\
40.4\end{array}$ & $\begin{array}{c}\text { per cent } \\
5.2 \\
3.9 \\
3.8 \\
9.7\end{array}$ & $\begin{array}{c}\text { per cent } \\
9.9 \\
8.0 \\
6.1 \\
22.5\end{array}$ & $\begin{array}{l}\text { per cent } \\
40-64 \\
36-60 \\
70-108 \\
24-60\end{array}$ \\
\hline
\end{tabular}

* Summary of 22 measurements made in female subjects collected from values reported by Lundsgaard and Van Slyke (16) ; Lundsgaard and Schierbeck (17); and Binger ( 3 ). Measurements made in sitting position throughout.

t Volume of air in the lungs midway between a normal expiration and inspiration.

volume of air in the lungs midway between a normal expiration and inspiration, and as a consequence the values of this subdivision, as well as those of the complementary air and the reserve air, are not comparable. All the measurements were made, furthermore, in the sitting posture, and for this additional reason they cannot be compared with our results since it has been demonstrated (2), (3), (13), (22) that change in body posture alters chiefly the mid capacity and the complementary and reserve volumes.

\section{RESULTS OF THIS INVESTIGATION}

In Table III are summarized the results of the determinations of the total pulmonary capacity and its subdivisions in the fifty healthy adult female subjects. The absolute and the relative (subdivisions expressed 


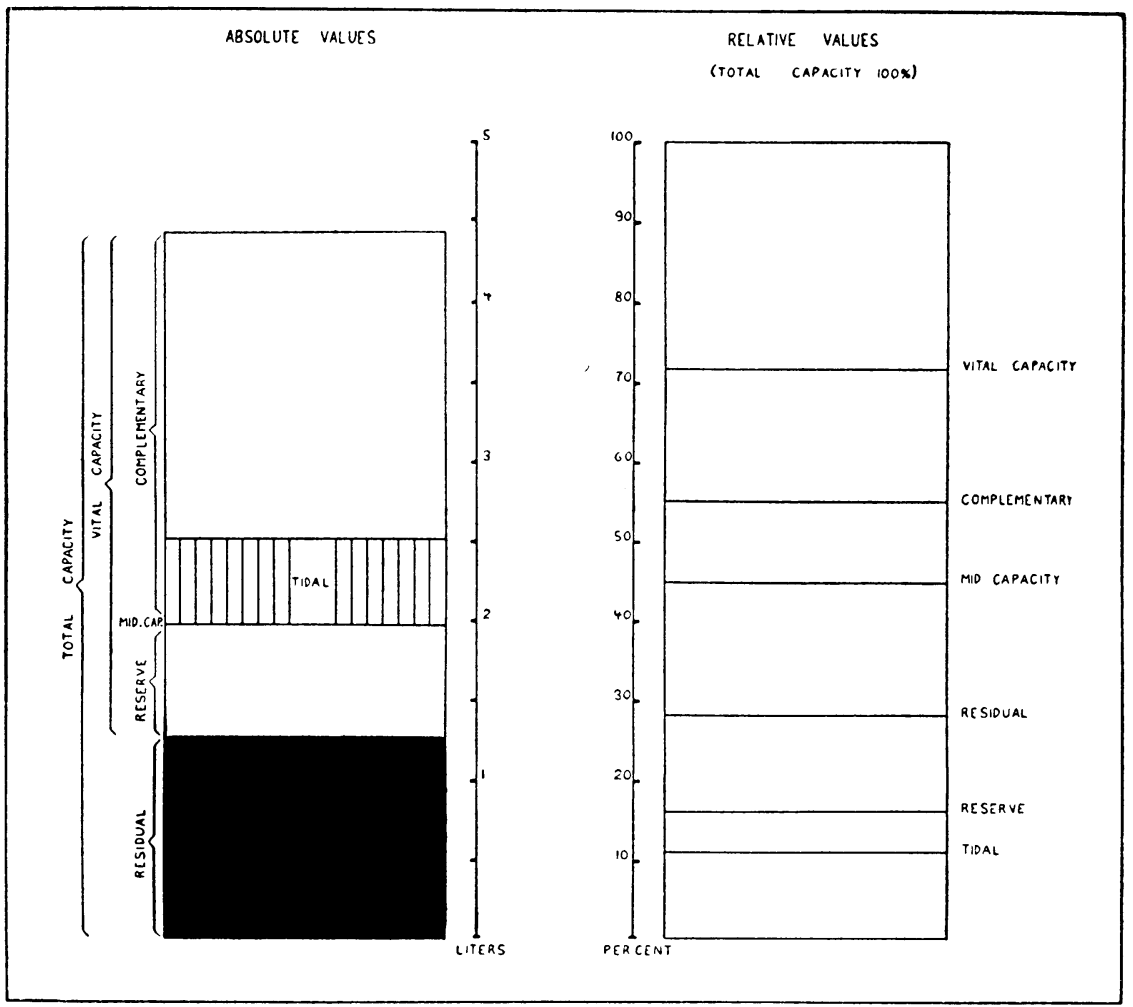

Fig. 2. Mean Absolute and Relative Values of Pulmonary Capacities in 50 Normal Female Subjects

as a percentage of the total and vital capacities) mean values, together with their deviation from the mean and the extreme variations, are presented.

Absolute values observed. The total capacity had a mean value of $4.41 \pm 0.06$ liters and a standard deviation of $0.59 \pm 0.04$ liter, indicating, therefore, a total variation of about 27 per cent. The variations fall between 3.33 and 6.38 liters. These values agree closely with those collected from the literature, respectively 4.41 and 0.62 liters for mean and standard deviation, with a total variation of 28 per cent.

The vital capacity also varied markedly. Its mean value was $3.14 \pm$ 0.04 liters, with a standard deviation of $0.41 \pm 0.03$ liter, giving a total variation around the mean of 26 per cent. This mean value corresponded almost exactly with that calculated from the literature, although in our series a somewhat higher degree of variation was found.

The mid capacity fluctuated widely. A mean value of $1.98 \pm 0.04$ liter, with a standard deviation of $0.40 \pm 0.03$ liter and a total variation of about 40 per cent were obtained. Its extreme values were 1.29 and 
TABLE III

Measurements of pulmonary capacity in 50 healthy female subjects

\begin{tabular}{|c|c|c|c|c|}
\hline \multirow[b]{2}{*}{$\begin{array}{l}\text { Pulmonary } \\
\text { capacity }\end{array}$} & \multicolumn{4}{|c|}{ Absolute values } \\
\hline & Mean & $\begin{array}{l}\text { Standard } \\
\text { deviation }\end{array}$ & $\begin{array}{c}\text { Coeff- } \\
\text { cient of } \\
\text { variation }\end{array}$ & Variations \\
\hline & liters & liters & per cent & liters \\
\hline Total capacity . . . . . . . . . . . . & $4.41 \pm 0.06^{*}$ & $0.59 \pm 0.04^{*}$ & 13.3 & $3.33-6.38$ \\
\hline Vital capacity......... & $3.14 \pm 0.04$ & $0.41 \pm 0.03$ & 13.0 & $2.28-3.95$ \\
\hline Complementary air. & $2.42 \pm 0.03$ & $0.36 \pm 0.02$ & 14.8 & $1.70-3.32$ \\
\hline Reserve air....... & $0.73 \pm 0.02$ & $0.19 \pm 0.01$ & 25.8 & $0.28-1.42$ \\
\hline Mid capacity ........... & $1.98 \pm 0.04$ & $0.40 \pm 0.03$ & 20.1 & $1.29-3.30$ \\
\hline Residual air........... & $1.25 \pm 0.03$ & $0.31 \pm 0.02$ & 24.6 & $0.67-2.46$ \\
\hline
\end{tabular}

Relative values (total capacity $=100$ per cent)

\begin{tabular}{|c|c|c|c|c|}
\hline & per cent & per cent & per cent & per cent \\
\hline Vital capacity..... & $71.6 \pm 0.49$ & $5.2 \pm 0.35$ & 7.2 & $61.5-82.8$ \\
\hline Complementary air. & $55.1 \pm 0.52$ & $5.4 \pm 0.36$ & 9.8 & $46.1-70.3$ \\
\hline Reserve air. . . . . . & $16.1 \pm 0.35$ & $3.7 \pm 0.25$ & 22.9 & $5.9-26.2$ \\
\hline Mid capacity . . . . . . . . & $44.7 \pm 0.50$ & $5.3 \pm 0.36$ & 11.8 & $29.6-53.8$ \\
\hline Residual air . . . . . . . . . . & $28.3 \pm 0.48$ & $5.0 \pm 0.34$ & 17.6 & $17.2-38.5$ \\
\hline
\end{tabular}

Relative values (vital capacity $=100$ per cent)

\begin{tabular}{|c|c|c|c|c|}
\hline & per cent & per cent & per cent & per cent \\
\hline Complementary air. & $77.0 \pm 0.72$ & $7.6 \pm 0.51$ & 9.8 & $64.1-92.2$ \\
\hline Reserve air... & $22.9 \pm 0.43$ & $4.6 \pm 0.31$ & 20.1 & $7.8-35.9$ \\
\hline Mid capacity. . . . & $63.3 \pm 1.06$ & $11.2 \pm 0.76$ & 17.6 & $38.8-85.5$ \\
\hline Residual air. . . . . . . . & $40.2 \pm 0.98$ & $10.3 \pm 0.69$ & 25.6 & $19.3-62.7$ \\
\hline
\end{tabular}

* Probable error.

3.30 liters. Comparison cannot be made with the values found in the literature on account of the different classification used.

The residual air presented even greater. variations, ranging between 0.67 and 2.46 liters (however, a volume of more than 2 liters was found in one case only). Its mean value was $1.25 \pm 0.03$ liter; the standard deviation $0.31 \pm 0.02$ liter, and consequently the total variation from the mean value was about 50 per cent. Again the mean value and the standard deviation compared closely with the corresponding figures found in the literature (1.23 and 0.28 liter. respectively).

The complementary and reserve volumes had mean values of $2.42 \pm$ 0.03 and $0.73 \pm 0.02$ liters respectively. They also showed marked fluctuations, especially in the case of the reserve air in which the total variation from the mean exceeded 50 per cent.

It is of interest that the variations shown in the absolute values in these female subjects correspond very closely with those found in the group 
of male subjects previously reported from this clinic (11). The coefficients of variation are almost similar in both series, although the mean absolute values differ markedly in the two sexes, as must be expected.

Relative values. The values found for the various subdivisions of the lung capacity may conveniently be expressed as percentages of the total capacity. As has been shown above, the absolute values of the total pulmonary capacity and its subdivisions differ widely among individuals; on the other hand, it has been found that, as in male subjects, the values for the various subdivisions relative to the total capacity have normally a fixed range of variation for all individuals. The ratio $\frac{\text { Vital capacity }}{\text { Total capacity }} \times 100$ had a mean value of $71.6 \pm 0.49$ per cent, with a standard deviation of only $5.2 \pm 0.35$ per cent, giving a total variation from the mean of less than 15 per cent. It may be recalled that in the series of normal males a similar constancy in the variations of this ratio was observed, indicating, therefore, a rather close relationship between vital capacity and residual volume as component parts of the total capacity. The constancy of this ratio is further confirmed on calculation of the results collected from the literature (Table II). The mean value is 72.0 per cent, with a standard deviation of 4.6, giving a total variation of about 13 per cent. The ratio $\frac{\text { Residual air }}{\text { Total capacity }}$ $\times 100$ presented corresponding fluctuations. It varied between 17.2 and 38.5 per cent, with a mean value of $28.3 \pm 0.48$ per cent, and a standard deviation of $5.0 \pm 0.34$.

The mid capacity showed wide but well defined variations in its relative value. A mean value of $44.7 \pm 0.50$ per cent, and a standard deviation of $5.5 \pm 0.36$ were obtained. The complementary and reserve volumes varied markedly as percentages of the total capacity, especially in the case of the latter.

The relationship between the different pulmonary capacities as expressed by the correlation coefficients ${ }^{5}$ may be seen in Table IV. The highest correlation is between the total and the vital capacities. The smaller subdivisions of the pulmonary capacity have also been expressed as percentages of the vital capacity. There are marked variations however, in these ratios (Table III). It is more useful, and in better agreement with most investigators, to use the total capacity as a basis for a comparison of the relative values of its components.

\section{Measurements of the respiratory "Dead space"}

The investigation of the respiratory "dead space," measured by the Haldane-Priestley formula (8) from the tidal volume and the $\mathrm{CO}_{2}$ per-

${ }^{5}$ Correlation coefficients are significant only when they exceed the probable error multiplied by three, and the correlation is proportionally better as coefficients approach the value of 1 . 
TABLE IV

\section{Correlation between the different subdivisions}

Capacities correlated

Correlation coefficient

Total capacity and vital capacity . . . . . . . . . . . . . $0.8860 \pm 0.0205^{*}$

Total capacity and complementary air............ $0.7485 \pm 0.0418$

Total capacity and reserve air .................... $0.4657 \pm 0.0742$

Total capacity and mid capacity ................ $0.7916 \pm 0.0351$

Total capacity and residual air. . . . . . . . . . . . $0.7146 \pm 0.0465$

Vital capacity and complementary air. . . . . . . . . $. .8+0.8742 \pm 0.0222$

Vital capacity and reserve air................... $+0.4942 \pm 0.0722$

Vital capacity and mid capacity ................. $0.5129 \pm 0.0701$

Vital capacity and residual air . . . . . . . . . . . . . . . $0.3518 \pm 0.0829$

Complementary air and mid capacity $\ldots \ldots \ldots \ldots \ldots \ldots \ldots+0.2635 \pm 0.0883$

Complementary air and reserve air................ $0.0643 \pm 0.0941$

Complementary air and residual air ............... $0.3647 \pm 0.0823$

Mid capacity and reserve air. . . . . . . . . . . . . . $\ldots+\ldots .5684 \pm 0.0641$

Mid capacity and residual air . . . . . . . . . . . . . . $0.8762 \pm 0.0261$

Residual air and reserve air . . . . . . . . . . . . . . $0.1994 \pm 0.0944$

* Probable error.

centages of the tidal and alveolar air were made in the sitting posture during rest (Table V). The volume of the "dead space" in our series had a mean value of $144 \pm 6.48 \mathrm{cc}$., corresponding to a mean tidal volume of $0.48 \pm 0.02$ liter, with a mean respiratory rate and ventilation per minute of $15 \pm 0.19$ and $6.86 \pm 0.15$ liters respectively. This observed value for the respiratory "dead space" corresponds very closely to those found by most investigators.

Concerning the true value of the respiratory "dead space," there is a great deal of controversy in the literature. In 1911 Siebeck (21) found that the "dead space" varies considerably in different individuals, and that it is increased during hyperpnea following muscular work. A year later Douglas and Haldane (6) concluded that the respiratory "dead

TABLE $\mathbf{v}$

Measurements of respiratory dead space in 50 healthy female subjects

\begin{tabular}{|c|c|c|c|c|}
\hline & Mean & $\begin{array}{l}\text { Standard } \\
\text { deviation }\end{array}$ & $\begin{array}{c}\text { Coeffi- } \\
\text { cient of } \\
\text { variation }\end{array}$ & Variations \\
\hline 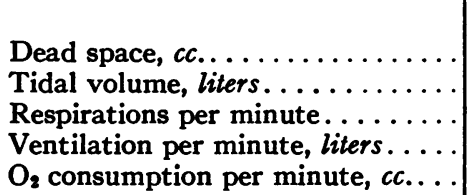 & $\begin{array}{r}144 \pm 6.48^{*} \\
0.48 \pm 0.02 \\
15 \pm 0.19 \\
6.86 \pm 0.15 \\
242.5 \pm 3.05\end{array}$ & $\begin{array}{r}\cdot \\
68 \pm 4.59 * \\
0.14 \pm 0.01 \\
2 \pm 0.13 \\
1.54 \pm 0.10 \\
32 \pm 2.16\end{array}$ & $\begin{array}{c}\text { per cent } \\
47.2 \\
29.1 \\
13.3 \\
22.4 \\
13.2\end{array}$ & $\begin{array}{l}41-449 \\
0.30-0.98 \\
10-21 \\
4.24-13.06 \\
152-320\end{array}$ \\
\hline
\end{tabular}

* Probable error. 


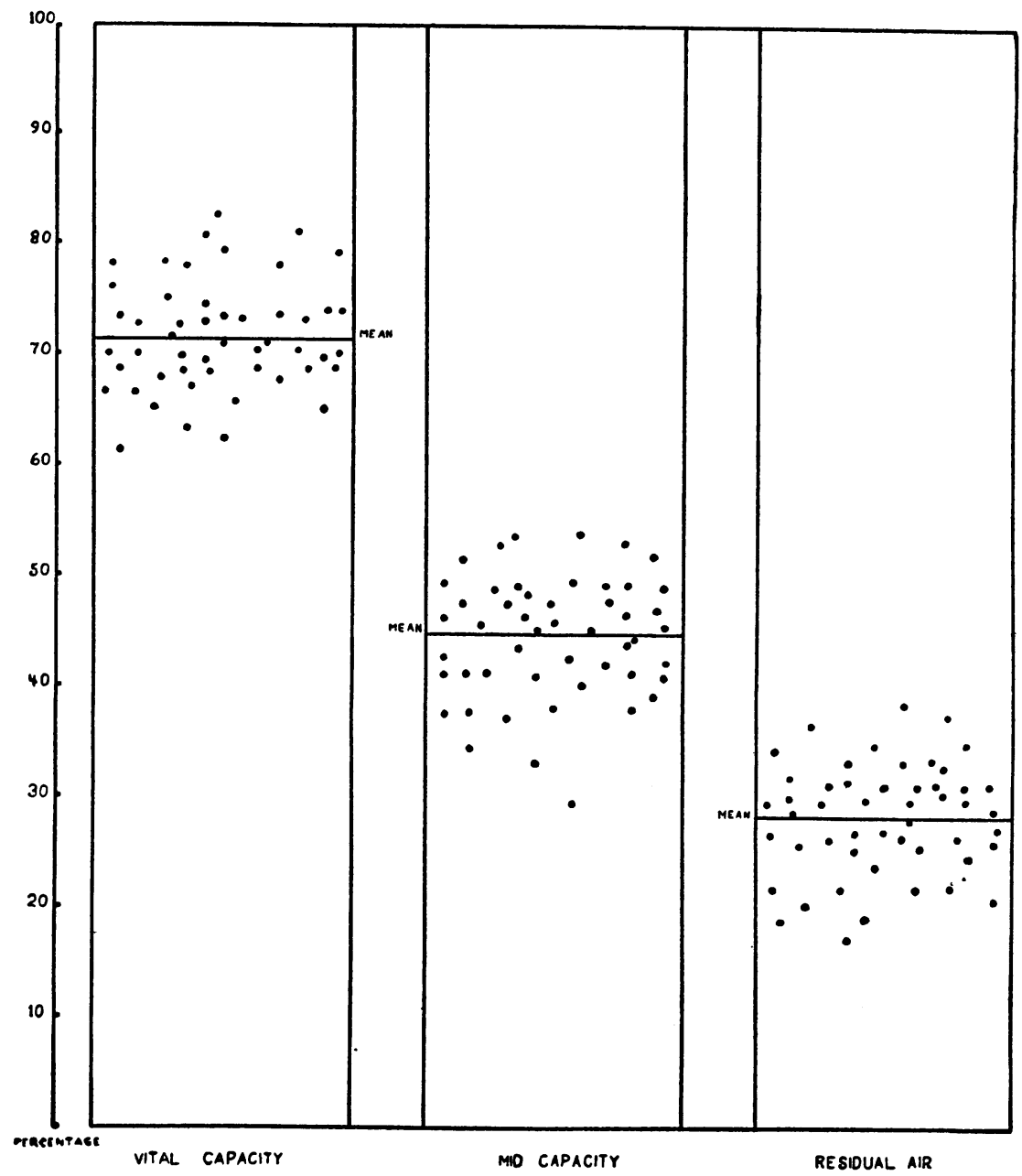

Fig. 3. Vital Capacity, Mid Capacity and Residual Air Expressed in Percentage of the Total Capacity

The dots indicate observations on 50 individuals grouped about the mean values.

space" is not a fixed anatomical quantity, but rather a physiological variable, closely and proportionally related to the depth of the breathing, being greater during hyperpnea with large tidal volumes, and less during quiet breathing. These findings were later confirmed both by Haldane (9), who believed that the variations are brought about by passive stretching of the atria (beyond the terminal bronchioles), and by Henderson, Chillingworth and Whitney (10), who made use of several different methods, and found that all yielded similar results in showing a close correlation with 
the depth of the breathing. They also showed that the respiratory "dead space" undergoes rhythmic variations in the same individual breathing with approximately the same tidal volume. These variations were found to be sometimes as high as 30 per cent.

These conclusions have, however, been criticized by Krogh and Lindhard (14), and also by Pearce and Hoover. (18), who put forward evidence to show that the respiratory "dead space" has a fixed volume in any individual, and is not influenced by the depth of the breathing. Their criticisms were based mainly on the contention that the Haldane-Priestley method for obtaining alveolar air is faulty, especially during hyperpnea. Later these criticisms have to some extent been modified. Krogh (15), although stating that under ordinary conditions of breathing there is very little variation in the respiratory "dead space," found evidence of increments amounting to as much as $100 \mathrm{cc}$. when very deep breaths were taken. Pearce and Hoover (19) in 1920 presented several observations which appeared to indicate that there is a definite and constant increase in the volume of the "dead space" with very deep breathing, although the increase was not so marked as that found by Haldane. They also concluded that the increment in volume of the "dead space," with increasing tidal volumes, is not a linear function of the depth of the inspiration, but a powered function. Several years ago Aitken and Clark-Kennedy (1) made fractional analysis of a single expiration during muscular activity, measuring the $\mathrm{CO}_{2}$ percentages of the various samples taken and calculating from them the respiratory "dead space." They also observed a moderate increase as the depth of the breathing increased, although not of the same magnitude as that observed by Douglas and Haldane.

In this series, considerable variations have been found. The standard deviation was $68 \pm 4.59 \mathrm{cc}$. (mean value of $144 \pm 6.48 \mathrm{cc}$.) with a total variation of about 95 per cent. On close analysis the respiratory dead space showed a definite correlation with the tidal volume, particularly when the latter was great (Table VI and Figure 4). With a tidal volume between 0.30 and 0.50 liter, the corresponding dead space varied between 50 and $150 \mathrm{cc}$., and there was no definite correlation demonstrable between the two. When the tidal volume was above 0.50 liter the volume of the

TABLE VI

$\begin{array}{ccc}\begin{array}{c}\text { Relationship of respiratory dead space to tidal volume } \\ \text { Tidal volume } \\ \text { liters } \\ \text { Number of cases }\end{array} & \begin{array}{c}\text { cad space } \\ \text { Average }\end{array} \\ 15 & 0.30-0.39 & 114 \\ 20 & 0.40-0.49 & 119 \\ 8 & 0.50-0.59 & 161 \\ 2 & 0.60-0.69 & 223 \\ 3 & 0.70-0.79 & 244 \\ 0 & 0.80-0.89 & \\ 2 & 0.90-0.99 & 358\end{array}$




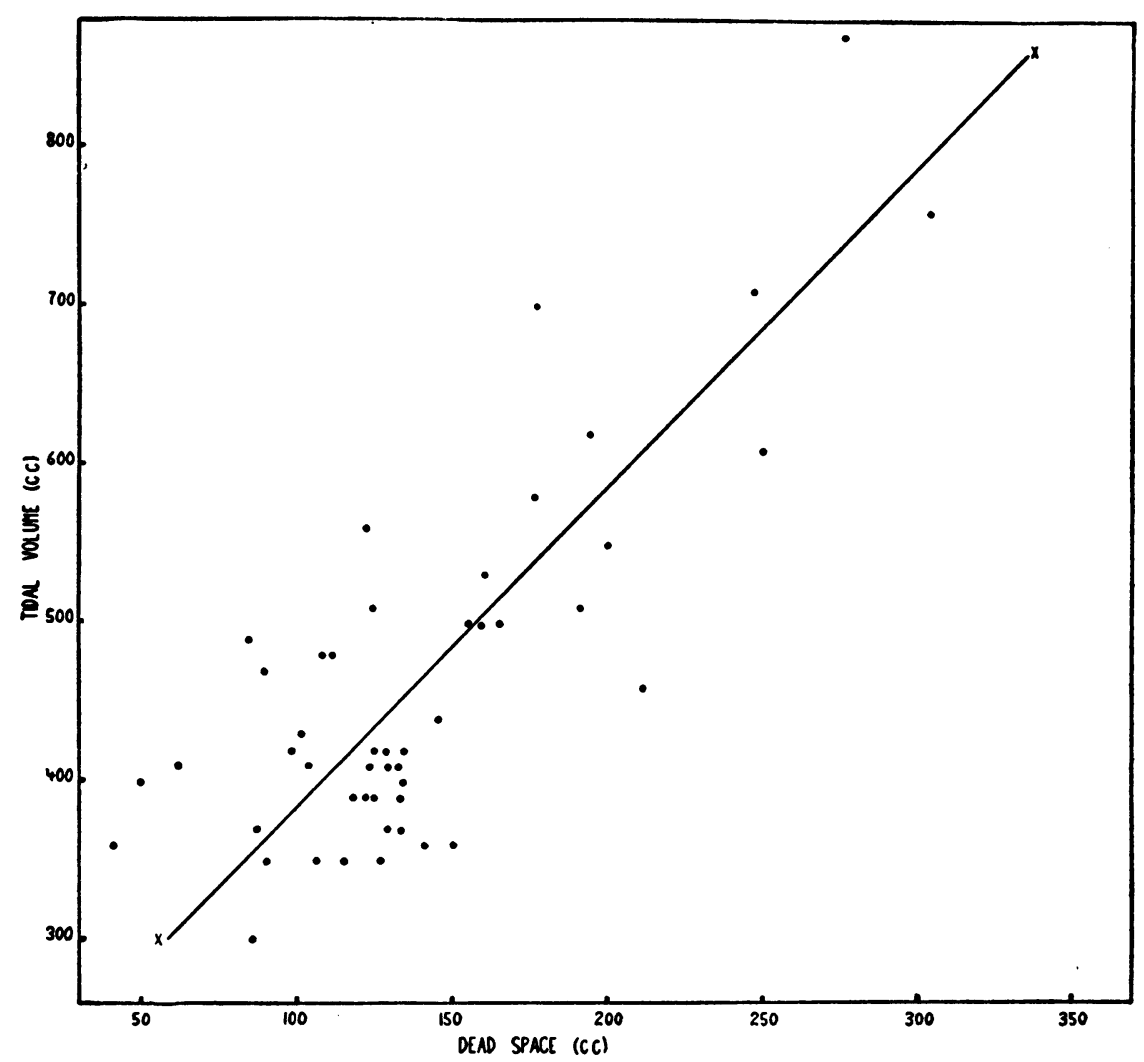

Fig. 4. Correlation between the Tidal Volume and the Respiratory "Dead SPace"

The curve $x-x$ represents the regression line derived from the correlation coefficient.

dead space was, however, definitely higher, and continued to increase in proportion to the depth of the breathing. The correlation coefficient ${ }^{6}$ between the tidal volume and the respiratory dead space was $+0.8224 \pm$ 0.0308 . The correlation was linear. as the correlation ratio was 0.8397 , giving an insignificant $\int n^{2}-r^{2}$ of $0.0288 \pm 0.0313$.

We have also observed, as Haldane has pointed out, that the variations in the volume of the dead space were independent of the respiratory rate. Using the method of partial correlation, it is found that if a constant respiratory rate in all fifty cases is assumed, the standard deviation corresponding to the value of the dead space will be only slightly reduced, becoming $66 \mathrm{cc}$. instead of $69 \mathrm{cc}$, i.e. a reduction of only 2.5 per cent.

- The regression equation derived from this correlation coefficient is as follows :

Dead space, $c c .=($ Tidal volume, liters $\times 494.9)-89.9$ 
On the other hand if a fixed tidal volume in all cases is assumed the corresponding standard deviation falls to 39 cc., i.e. a reduction of 43 per cent. The influence of the depth of breathing on the volume of the respiratory dead space is thus made strikingly apparent.

It seemed probable that a relationship exists between the respiratory "dead space" and the mid capacity (amount of air remaining in the lungs after a normal expiration). Observations were made in twelve cases in which the mid capacity was measured in the sitting posture a few minutes after the measurement of the dead space. In these twelve cases the average "dead space" was 149 cc. corresponding to an average tidal volume of 0.50 liter. The correlation coefficient between the two was $+0.9023 \pm$ 0.0391 . If the respiratory "dead space" is correlated directly with the mid capacity the insignificant correlation coefficient of $+0.3387 \pm 0.1881$ is obtained. Applying again the method of partial correlation, and assuming a constant tidal volume in all twelve cases, the correlation coefficient rises, however, to $+0.6320 \pm 0.1349$, which indicates a definite relationship between the mid capacity and the volume of the "dead space." In other words, in any two subjects, if both breathe with the same tidal volume, the one with the larger mid capacity will tend to have the larger dead space. Assuming constant tidal and mid capacity volumes in this series of twelve cases, the standard deviation of the value of the respiratory "dead space" falls from $76 \mathrm{cc}$. to $25.4 \mathrm{cc}$., i.e. a reduction of 66.6 per cent. This quantity would seem to represent the true variation of the volume of the "dead space," independent of the influence of the tidal volume and mid capacity.

It is of interest finally, briefly to mention the results of measuring the respiratory " dead space" calculated in 41 cases on the basis of the $\mathrm{O}_{2}$ percentages of the tidal and alveolar airs, according to the formula (10): Dead space $=$ Tidal volume $-\left(\right.$ Tidal volume $\left.\times \frac{20.93-\mathrm{O}_{2} \text { per cent tidal air }}{20.93-\mathrm{O}_{2} \text { per cent alveolar air }}\right)$. In these 41 cases, the mean oxygen percentages of the tidal and alveolar airs were $16.98 \pm 0.05$ and $14.14 \pm 0.08$ per cent respectively. The corresponding mean respiratory "dead space" was $158 \pm 10.51 \mathrm{cc}$., in contrast to the value $147 \pm 7.25$ obtained by using the $\mathrm{CO}_{2}$ percentages for the calculation. The finding of a higher value for the volume of the "dead space" on the basis of the oxygen percentages agrees with the observations of Haldane (9), and Henderson, Chillingworth and Whitney (10), who explained the difference as due to the diffusion of $\mathrm{CO}_{2}$ in considerable amounts from the walls of the mouth, trachea and bronchi.

A closer comparison between the values obtained for the respiratory " dead space" calculated respectively from the $\mathrm{CO}_{2}$ and the $\mathrm{O}_{2}$ percentages of the tidal and alveolar airs in our 41 cases may be summarized as follows: In 11 cases ( 26.8 per cent) the "dead space," as found by both methods, agreed within $10 \mathrm{cc}$. or less; the "dead space" calculated from the $\mathrm{O}_{2}$ 
percentages in 18 cases (43.9 per cent) was $10 \mathrm{cc}$. or larger; and, in 12 cases (29.2 per cent) was $10 \mathrm{cc}$. or more smaller. The larger values obtained from using the oxygen percentages were chiefly observed in those cases with large tidal volumes. Thus, in 30 cases in which the tidal volume was below 0.50 liter, the " dead space" calculated from the $\mathrm{O}_{2}$ percentages was on an average only $0.3 \mathrm{cc}$. per case larger. than that calculated from the $\mathrm{CO}_{2}$ percentages; but in the remaining 11 cases in which the tidal volume was above 0.50 liter, the "dead space" by the $\mathrm{O}_{2}$ method was 30.5 cc. larger on the average than when based on the $\mathrm{CO}_{2}$ percentages. The greatest differences (106 cc. and $123 \mathrm{cc}$.) were observed in two cases, which also showed the highest tidal volumes $(0.76$ and 0.91 liter respectively). These findings are consistent with the explanation advanced by Henderson, Chillingworth and Whitney, since it would seem likely that the greater the tidal volume the greater the chance of increased $\mathrm{CO}_{2}$ diffusion into the respiratory passages.

The variations in the values obtained for the respiratory "dead space" were more marked when measurements were made on the basis of the oxygen percentages. In the 41 cases so investigated, the coefficient of variation was 63.2 per cent, as compared with the value 48.7 per cent obtained when the "dead space" was calculated from the $\mathrm{CO}_{2}$ concentration in the tidal and alveolar airs.

\section{Correlation with physical and radiological measurements}

In the case of the total capacity, the highest correlation observed is that given with the "radiological chest volume" (area of the lung fields at maximum inspiration multiplied by the depth of the chest in the same respiratory position). The correlation coefficient is $+0.6294 \pm 0.0573$ (Table VII). The next most significant correlation is with the area of the lung fields at maximum inspiration, where the correlation coefficient is $+0.6218 \pm 0.0585$. Correlations with the external measurements of the chest, represented by the chest volume (external), with the body height, weight and surface area are all lower and, in some instances, statistically insignificant.

The vital capacity also shows its highest correlation (and, incidentally, the highest correlation in the total series) with the " radiological chest volume." The correlation coefficient is $+0.7073 \pm 0.0476$. Similarly, its next best correlation is that shown with the area of the lung fields, while correlations with the external chest volume and with other physical characteristics are again comparatively low or valueless. The mid capacity and the residual air have no correlation with the external chest measurements at the corresponding respiratory positions of mid capacity and maximum deflation. The observed correlations are in complete agreement with, and confirm those previously found in adult male subjects (12). In that series, the total capacity also was found to be best correlated with the " radiological 
TABLE VII

Correlation of pulmonary capacities with physical and radiological measurements

Characteristics correlated

Total capacity and body height.

Total capacity and body weight

Total capacity and body surface area

Total capacity and chest volume (external) (maximum inspiration) $\ldots \ldots \ldots \ldots \ldots \ldots \ldots \ldots \ldots \ldots \ldots \ldots \ldots \ldots \ldots \ldots \ldots \ldots \ldots+0.3520 \pm 0.0829$

Total capacity and area of lung fields (maximum inspiration) $\ldots+0.6218 \pm 0.0585$

Total capacity and radiological chest volume (maximum inspiration $\ldots \ldots \ldots \ldots \ldots \ldots \ldots \ldots \ldots \ldots \ldots \ldots \ldots \ldots \ldots \ldots \ldots \ldots+0.6294 \pm 0.0573$

Vital capacity and body height. . . . . . . . . . $\ldots \ldots \ldots \ldots \ldots+0.5134 \pm 0.0677$

Vital capacity and body weight ...................... $0.2604 \pm 0.0883$

Vital capacity and body surface area . . . . . . . . . . . . . $0.3378 \pm 0.0843$

Vital capacity and chest volume (external) (maximum inspiration) ................................. $0.3292 \pm 0.0850$

Vital capacity and area of lung fields (maximum inspiration) .... $+0.5983 \pm 0.0612$

Vital capacity and radiological chest volume (maximum inspiration)

Mid capacity and chest volume (external) (mid) . . . . . . . $0.1959 \pm 0.0917$

Residual air and chest volume (external) (maximum expiration) . + $0.1770 \pm 0.0924$

* Probable error.

chest volume," the correlation coefficient being $+0.6366 \pm 0.0566$ as compared with $+0.6294 \pm 0.0573$ observed in this series. The vital capacity in the male series similarly showed its highest correlation with the " radiological chest volume" $:+0.7174 \pm 0.0467$, as compared with $+0.7073 \pm$ 0.0476 obtained in this investigation. The other correlation coefficients also agree very closely in the two series, confirming the fact, already emphasized (12), that the pulmonary capacity is most closely correlated and may be predicted with a high degree of accuracy using combined radiological and external chest measurements (" radiological chest volume"). The observation in normal female subjects as in normal male subjects, of poor. correlation between the vital capacity and the body surface area is further evidence that this measurement constitutes an unsatisfactory basis for estimating the corresponding normal vital capacity, and this seems particularly the case in individuals in whom there is an imperfect balance between body height and weight.

In female subjects we have again been unable to confirm the findings of Lundsgaard and Van Slyke (16), which seemed to indicate the existence of a close correlation between the total pulmonary capacity and its subdivisions with the chest volume calculated by external measurements of the chest. It is evident that such a method fails to take into account the level of the diaphragm, and consequently gives an imperfect representation of the true size of the chest cavity. 


\section{Prediction of the normal capacity of the lungs}

Since of all the characteristics investigated both in male (12) and female subjects the highest correlation discovered has proved to be that existing between the vital capacity and the "radiological chest volume," the method of predicting the total pulmonary capacity and its main subdivisions in any given case remains substantially the same. It must be emphasized, however, that since the absolute as well as the relative values differ in the sexes, the formulae also differ. Knowing only the "radiological chest volume" the corresponding vital capacity may be predicted by means of the regression formula ${ }^{7}$ calculated from the correlation coefficient between these two quantities, while in turn other subdivisions and the total capacity may be derived from the predicted vital capacity by making use of the fixed relative values found for these components.

The method of calculation may be illustrated by the following example: (a) The area of the lung fields at maximum inspiration, as measured on the radiological film, is $\mathbf{5 2 0}$ square centimeters. The external anteroposterior diameter of the chest in the same respiratory position is $20 \mathrm{~cm}$. Therefore the "radiological chest volume" is $520 \times$ $20=10.40$ liters.

(b) The corresponding vital capacity would then be (according to the regression formula $):(10.40 \times 0.214)+0.95=3.18$ liters.

(c) The total capacity would be (taking into consideration that the vital capacity is 71.6 per cent of the total capacity) : $\frac{3.18}{71.6} \times 100=4.44$ liters.

(d) The residual air is equal to the total capacity minus the vital capacity: $4.44-3.18=1.26$ liters.

(e) The mid capacity would be (taking into account the fact that the mid capacity is 44.7 per cent of the total capacity): $\frac{4.44 \times 44.7}{100}=1.98$ liters.

Between the predicted and the observed values, there is, as in the male series, a very close correspondence (Figure 5). A variation of more than 15 per cent from the calculated values of the observed total and vital capacities, and of more than 30 and 40 per cent in the mid capacity and residual volumes respectively may be considered abnormal. The limits of variation for the latter volumes may appear to be considerable, but the volumes are relatively small and show wide physiological variations in the absolute values.

Since the investigation of normal male subjects was reported a large number of observations in cases of chronic pulmonary disease has been

7 The regression formula is:

Vital capacity, liters $=($ " radiological chest volume" liters $\times 0.214)+0.95$ 


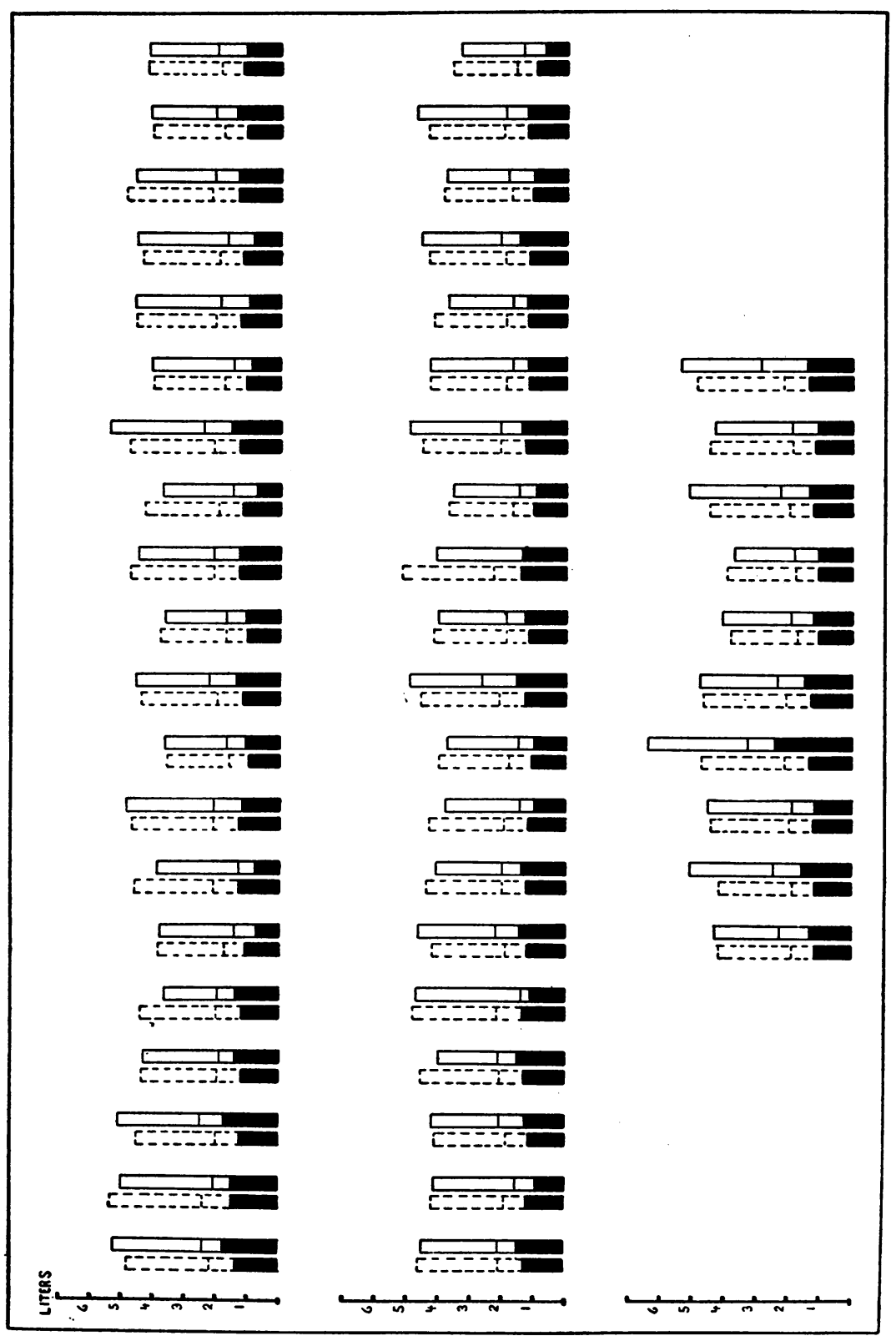

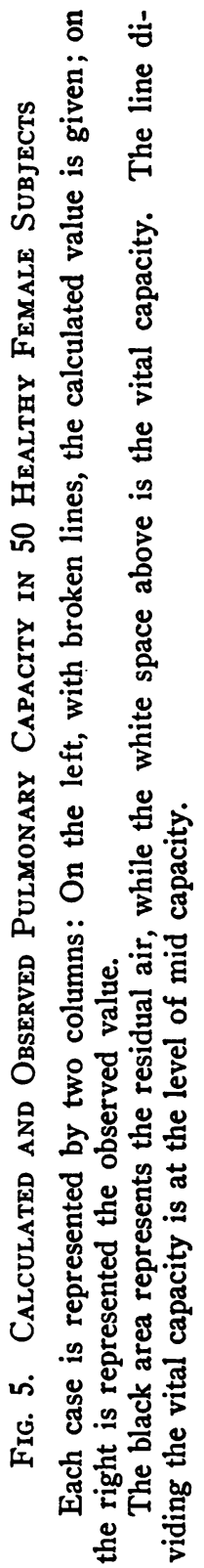


accumulated. The application of the limits of normal variations has been found to be useful in the detection of the pulmonary abnormality, and in the appreciation of the degree of functional respiratory disability.

\section{Chest expansion and pulmonary capacity}

The expansion of the chest estimated by external measurements showed marked variations, and bore no relationship to the absolute or relative pulmonary capacities. Radiological measurements made with a doubly exposed film furnished, on the other hand, more definite criteria for the appreciation of the normal range of expansion. In the ratio Area at maximum expiration

Area at maximum inspiration $\times 100$, the mean value was $63.6 \pm 0.49$ per cent, the standard deviation only $5.1 \pm 0.34$, and the resultant total variation only 16 per cent. These findings are similar to those observed in normal male subjects in whom the mean value of this ratio was $62.2 \pm 0.42$, the standard deviation $4.4 \pm 0.30$, and the total variation 14 per cent, and afford confirmation, therefore, of the restricted and fixed limits of variation of this ratio in normal subjects. According to these observations, if this ratio exceeds 75 per cent in a female subject a reduction in the expansion of the chest may be assumed to exist. This ratio of course fails to take into consideration the expansion in the anteroposterior diameter of the chest, but since this is very nearly equal to the lateral expansion (2.9 and $3.1 \mathrm{~cm}$. respectively as measured externally) it may be inferred that alterations in the former may possibly be reflected equally in the latter and thus appreciated in the radiological measurement.

It is of interest to find in female, as in normal male subjects, that the ratio $\frac{\text { Area at maximum expiration }}{\text { Area at maximum inspiration }} \times 100$ bears a relationship to the corresponding relative pulmonary capacity. If it is correlated with $\frac{\text { Residual air }}{\text { Total capacity }} \times 100$ the correlation coefficient is $+0.5189 \pm 0.0695$, indicating that diminished chest expansion tends to be accompanied by a high proportion of residual air to the total capacity, or in other words by probably defective alveolar ventilation.

Other radiological measurements of chest expansion presented marked variations, but it seems probable that on occasion they offer additional information in explanation of the mechanism of decrease in expansion. The excursion of the diaphragm, the expansion in the width of the chest and the rib movement may, for example, be considered to be abnormally reduced if they are less than $2.5,2.0 \mathrm{~cm}$. and $12^{\circ}$ respectively.

Individuals with broad chests and high diaphragmatic levels (hypersthenic type) frequently have small volumes of reserve air. The same observation was made in male subjects. This type of chest tends to exhibit a small pulmonary area in roentgenograms and correspondingly 
lower pulmonary capacity, when compared with chests of the long slender type in which the diaphragmatic level is low (asthenic type).

TABLE VIII

Measurements of chest expansion

\begin{tabular}{|c|c|c|c|c|}
\hline & \multicolumn{4}{|c|}{ External measurements } \\
\hline & Mean & $\begin{array}{l}\text { Standard } \\
\text { deviation }\end{array}$ & $\begin{array}{c}\text { Coeffi- } \\
\text { cient of } \\
\text { variation }\end{array}$ & Variations \\
\hline $\begin{array}{l}\text { Lateral expansion, } c m . . \ldots \ldots \ldots \\
\text { Anteroposterior expansion, } \mathrm{cm} \ldots\end{array}$ & $\begin{array}{l}3.1 \pm 0.07 \\
2.9 \pm 0.07\end{array}$ & $\begin{array}{l}0.8 \pm 0.05^{*} \\
0.8 \pm 0.05\end{array}$ & $\begin{array}{c}\text { per cent } \\
25.8 \\
27.5\end{array}$ & $\begin{array}{l}1.5-5.0 \\
1.5-4.5\end{array}$ \\
\hline \multicolumn{5}{|c|}{ Radiological measurements } \\
\hline $\begin{array}{r}\text { Excursion of diaphragm, right, } \mathrm{cm} . \\
\text { left, } \mathrm{cm} . \\
\text { Expansion in chest width, } \mathrm{cm} . \ldots \\
\text { Rib movement, degrees. } \ldots \ldots \ldots \\
\frac{\text { Area at maximum expiration }}{\text { Area at maximum inspiration }} \times 100\end{array}$ & $\begin{array}{r}5.0 \pm 0.12 \\
5.0 \pm 0.12 \\
3.4 \pm 0.06 \\
24 \pm 0.40 \\
63.6 \pm 0.49\end{array}$ & $\begin{array}{l}1.3 \pm 0.09 \\
1.3 \pm 0.09 \\
0.7 \pm 0.04 \\
4.2 \pm 0.28 \\
5.1 \pm 0.34\end{array}$ & $\begin{array}{r}26.0 \\
26.0 \\
20.6 \\
17.4 \\
8.0\end{array}$ & $\begin{array}{c}2.4-7.4 \\
1.5-7.3 \\
1.2-5.5 \\
11-33 \\
51.7-75.6\end{array}$ \\
\hline
\end{tabular}

* Probable error.

\section{SUMMARY AND CONCLUSIONS}

Measurements of total pulmonary capacity and its subdivisions have been made in 50 healthy female subjects of an average age of 23 years. The physical characteristics of the subjects examined are fully presented. The technique and methods described in previous papers $(11),(12)$ have been used. Normal values gathered from the literature are summarized.

The results obtained in healthy female subjects, confirm the findings and conclusions reached in a similar study of fifty healthy male subjects, but at the same time indicate the necessity of utilizing separate normal values for the two sexes.

Measurements of the respiratory "dead space" have also been made, using the Haldane-Priestley formula in calculation, involving the $\mathrm{CO}_{2}$ and the $\mathrm{O}_{2}$ percentages of the tidal and alveolar air, and the tidal volume.

The observations presented lead to the following conclusions:

1. In normal adult female subjects there are marked individual variations in the absolute values of the total pulmonary capacity and its subdivisions. They are closely correlated, however, with the "radiological chest volume," calculated from radiological and external chest measurements. A formula has been developed which permits the prediction of the normal pulmonary capacity and its main subdivisions in any given case. 
2. A variation from the predicted values of more than 15 per cent in the observed total and vital capacities, and of more than 30 and 40 per cent in the mid capacity and residual air respectively, may be considered to be significant and beyond the normal limits of variation.

3. The vital capacity, mid capacity and residual air fluctuate within definite limits if expressed in percentage of the total capacity. Alveolar ventilation is probably defective in any case in which the ratio $\frac{\text { Vital capacity }}{\text { Total capacity }} \times 100$ is lower than 60 per cent, or if correspondingly the ratio $\frac{\text { Residual air }}{\text { Total capacity }} \times 100$ is higher than 40 per cent.

4. The volume of the respiratory "dead space" is independent of the rate of the breathing, but varies with its depth. An increase in "dead space" becomes evident whenever the tidal volumes exceed 0.50 liter. The correlation is linear and positive. The "dead space" is also found to be correlated with the mid capacity, although to a lower degree.

5. The respiratory "dead space" calculated on the basis of the oxygen content of the tidal and alveolar air is larger than that calculated from the corresponding carbon dioxide content, when the tidal volume exceeds 0.50 liter.

6. The chest expansion may best be appreciated from measurements of the areas of the lung fields at maximum expiration and inspiration shown on a radiological film. If the ratio $\frac{\text { Area at maximum expiration }}{\text { Area at maximum inspiration }}$ $\times 100$ is higher than 75 per cent the chest expansion may be considered to be abnormally small. There is a positive correlation between this ratio and the proportion of residual air to total capacity, indicating that a decrease in the expansion of the chest tends to be accompanied by a less effective pulmonary ventilation.

\section{BIBLIOGRAPHY}

1. Aitken, R. S., and Clark-Kennedy, A. E., On the fluctuation in the composition of the alveolar air during the respiratory cycle in muscular exercise. J. Physiol., 1928, 65, 389.

2. Anthony, A. J., Untersuchungen über Lungenvolumina und Lungenventilation. Deutsches Arch. f. klin. Med., 1930, 167, 129.

3. Binger, C. A. L., The lung volume in heart disease. J. Exper. Med., 1923, 38, 445.

4. Binger, C. A. L., and Brow, G. R., Studies on the respiratory mechanism in lobar pneumonia. A study of lung volume in relation to the clinical course of the disease. J. Exper. Med., 1924, 39, 677.

5. Christie, R. V., The lung volume and its subdivisions. I. Methods of measurements. J. Clin. Invest., 1932, 11, 1099.

6. Douglas, C. G., and Haldane, J. S., The capacity of the air passages under varying pathological conditions. J. Physiol., 1912-13, 45, 235. 
7. Fridericia, L. S., Eine klinische methode zur bestimmung der Kohlensäurespannung inder Lungenluft. Berl. klin. Wchnschr., 1914, 27, 268.

8. Haldane, J. S., and Priestley, J. G., The regulation of the lung ventilation. J. Physiol., 1905, 32, 225.

9. Haldane, J. S., The variations in the effective dead space in breathing. Am. J. Physiol., 1915, 38, 20.

10. Henderson, Y., Chillingworth, F. P., and Whitney, J. L., The respiratory dead space. Am. J. Physiol., 1915, 38, 1.

11. Hurtado, A., and Boller, Ch., Studies of total pulmonary capacity and its subdivisions. I. Normal, absolute and relative values. J. Clin. Invest., 1933, $12,793$.

12. Hurtado, A., and Fray, W. W., Studies of total pulmonary capacity and its subdivisions. II. Correlation with physical and radiological measurements. J. Clin. Invest., 1933, 12, 807.

13. Hurtado, A., and Fray, W. W., Studies of total pulmonary capacity and its subdivisions. III. Changes with body posture. J. Clin. Invest., 1933, $12,825$.

14. Krogh, A., and Lindhard, J., The volume of the "dead space" in breathing. J. Physiol., 1913-14, 47, 30.

15. Krogh, A., and Lindhard, J., The volume of the dead space in breathing and the mixing of gases in the lungs. J. Physiol., 1917, 51, 59.

16. Lundsgaard, C., and Van Slyke, D. D., Studies of lung volume. I. Relation between thorax size and lung volume in normal adults. J. Exper. Med., 1918, 27, 63.

17. Lundsgaard, C., and Schierbeck, $K$., Untersuchungen über die volumina den lungen. IV. Die Verhältnisse bei Patienten mit Lungenemphysem. Acta med. Scandinav., 1923, 58, 541.

18. Pearce, R. G., and Hoover, D. H., Studies in the Physiology of the Respiration. III. The $\mathrm{O}_{2}$ and $\mathrm{CO}_{2}$ dead space in man. Am. J. Physiol., 1917, 44, 391.

19. Pearce, R. G., and Hoover, D. H., Variations in the respiratory dead air space due to changes in the depth of the breathing. Am. J. Physiol., $1920,52,472$.

20. Peters, J. P., and Van Slyke, D. I, Quantitative Clinical Chemistry. II. Methods. Williams and Wilkins Co., Baltimore, 1932.

21. Siebeck, R., Uber den Gasaustausch zwischen aubenluft und alveolen. Zweite mitteilung über die bedeutung und Bestimmung des "schädlichen Rammes" bei der Atmung. Scandinav. Arch. f. Physiol., 1911, 25, 81.

22. Wilson, W. H., The influence of posture on the volume of reserve air. J. Physiol., 1927-28, 114, 54. 